\title{
Racial variation of a non-fluorescent segment of the Y chromosome in East Indians*
}

\author{
RAM S VERMA, AFROZA HUQ $\dagger$, AND HARVEY DOSIK \\ From the Departments of Laboratories and Medicine, The Jewish Hospital and Medical Center of Brooklyn, \\ New York and State University of New York Downstate Medical Center, Brooklyn, New York, USA.
}

SUMMARY Seventy normal male East Indians were selected to study the length of the fluorescent (f), non-fluorescent (nf), and total length of the $Y$ chromosome by the QFQ technique. The length of the $\mathrm{Y}$ chromosome was classified into five groups using subjectively defined criteria, namely, very small, small, average, large, and very large. The frequencies of $\mathrm{Y} / \mathrm{F}$ indices for these groups were $0.0 \%, 1.42 \%, 15.71 \%, 58.57 \%$, and $24.28 \%$, respectively. The variation in the total length of the $\mathrm{Y}$ chromosome was accounted for by variations in the length of the $\mathrm{nf}$ as well as the $\mathrm{f}$ segments. The mean $\mathrm{Y} / \mathrm{F}, \mathrm{f} / \mathrm{F}$, and $\mathrm{nf} / \mathrm{F}$ indices for East Indians were $1 \cdot 20,0 \cdot 47$, and $0 \cdot 73$, respectively. A longer $\mathrm{Y}$ was noted in East Indians primarily owing to an increase in size of the nf segment in comparison to normal black and Caucasian populations. Furthermore, it is emphasised that the definition of 'average' or 'large' $Y$ varies from race to race.

Size variation (polymorphism or heteromorphism) of the long arm of the human $\mathrm{Y}$ chromosome from person to person and even from one ethnic group to another was established even before the banding era, ${ }^{1-3}$ and its inheritance at constant length is a documented fact. ${ }^{4-6}$ By the QFQ ( $Q$ bands by fluorescence using quinacrine) technique, $^{78}$ the long arm of the human $Y$ (Yq) chromosome differentiates into two segments, namely nonfluorescent (nf) and fluorescent (f), and the two segments have been designated Yq11 and Yq12, respectively. ${ }^{9}$ The variation in the length of the $Y$ chromosome has previously been reported as resulting from the $f$ segment while the nf segment remained constant. ${ }^{10-14}$ However, three preliminary studies, including one of our own, indicate that the nf segment may also be responsible for the length variation..$^{15-17}$ Our preliminary survey of the chromosomes of East Indians suggested the presence of a longer $\mathrm{Y}$ chromosome. This provided us with a unique opportunity to determine whether the nf segment as well as the f segment is variable in size and, if so, whether the increased size of the $Y$ chromosome is determined by an increase in one or both segments. Furthermore, the degree of size

\footnotetext{
* This work was presented in part at the 32nd Annual Meeting of the American Society of Human Genetics, Dallas, Texas, USA.

$\dagger$ AH was a research fellow at the Jewish Hospital and Medical Center of Brooklyn.
}

Received for publication 2 August 1982. correlation ( $r$ ) between the $f$ and $n f$ segments was measured using extensive statistical analyses.

\section{Materials and methods}

The 70 East Indians were all healthy and between the ages of 28 and 45 years. Sixty Caucasian and 60 American blacks were taken from our previous survey. ${ }^{1718}$ All subjects had negative medical histories and were unrelated. The length of the $Y$ chromosome was not known at the time of selection for the study. All chromosome preparations were made from cultured peripheral blood. ${ }^{19}$ The QFQ technique was carried out 3 to 7 days after harvesting. QFQ cells were photographed on tri-X pan film using a Zeiss photomicroscope II. ${ }^{20} 21$ At least 20 to 30 cells were photographed from each person and more than 4500 cells were photographed from the three populations.

The five best differentiated cells were selected from each person. Chromosomes were measured directly from the negative film, as a considerable amount of information is lost during printing. All possible variables were taken into consideration to ensure optimal results. ${ }^{22}$ Cells were projected by a Simmon Omega Point Light Source Enlarger (Simmon Omega Inc, NY, magnification $\times 8000$ ). All chromosomes 19 and 20 (that is, F group chromosomes) were measured. The total $Y$ length and the fluorescent (f) and non-fluorescent (nf) 
segments were measured in the same cell. The value of $F$ was based on the average lengths of chromosomes 19 and 20. From these measurements, the ratio $Y / F, f / F$, and $n f / F$ were determined for each cell and the average was taken from five cells.

In order to determine the 'functional relationship' of one variable (for example, length of $f$ segment vs total length of $Y$, etc) with another, a regression coefficient analysis was performed. A 'function' is a mathematical relation enabling us to predict what value of a variable $Y$ corresponds to given values of a variable $\mathrm{f}$, etc. A $\mathrm{Y}$ intercept (a) and regression coefficient (b) was calculated to determine the regression equation. A test of significance of the regression coefficient was also performed. Correlation coefficient ( $r$ ) analysis was used to examine the degree to which two variables vary together. Once established, such an association is likely to lead to reasoning about causal relations between the variables. Test of significance and confidence limits for correlations (r) were also calculated. Since we are dealing with proportions, the 'angular transformation' was used to test the significance of $\mathrm{nf}$ as well as $\mathrm{f}$ segments of the $\mathrm{Y}$ chromosomes. The frequency distribution was also tested by the $\chi^{2}$ test. Confidence limits and standard deviations of means were also calculated to provide better magnitudes of statistical parameters. ${ }^{24}$

\section{Results and discussion}

The length of the human $\mathrm{Y}$ chromosome was classified into five classes, namely very small, small, average, large, and very large. The logic behind this classification has been suggested elsewhere. ${ }^{1718}$ The previous surveys were done by using similar conditions and criteria to describe the variation of the human $Y$ chromosome. The frequency distribution of the $\mathrm{Y} / \mathrm{F}$ index within each class interval is compared in table 1 with two other groups. There was only $1.42 \%$ of East Indians that had a small $\mathrm{Y}$, while this class was $15 \%$ in Caucasians and $3.33 \%$ in blacks. The distribution of $\mathrm{Y} / \mathrm{F}$

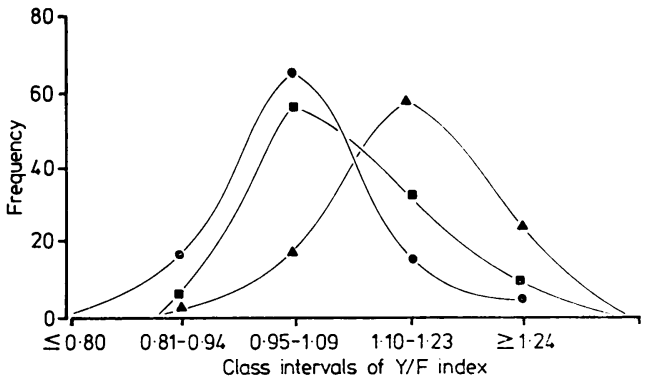

FIG 1 Distribution of $Y / F$ indices among East Indians

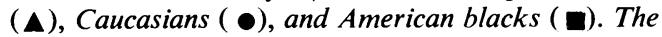
data are taken from table 2.

indices of the five classes is shown in fig 1 and it is clearly demonstrated that there was a normal distribution of $\mathrm{Y} / \mathrm{F}$ indices among Caucasians and Indians, while the black population showed a skewed curve (skewed to the left). Therefore, to compare the average length of the $Y$ chromosome from one group to another is inappropriate. At this point it would be useful to determine the significance of the categories. Obviously, the definition of a large $\mathrm{Y}$ will depend upon what race one is dealing with. For example, if we say that average should represent the most frequent class (with $\mathrm{Y} / \mathrm{F}$ index of 0.95 to 1.09 ), then only Caucasians and blacks will conform to this. In the Indian population, the most frequent class was large, while average was only third in frequency.

Long $Y$ chromosomes, according to the definition of Court-Brown, ${ }^{25}$ are either as long as or longer than F group (19 and 20) chromosomes. Generally, the length of the $Y$ chromosome has been classified into two categories, short or long, depending on the value of the $\mathrm{Y} / \mathrm{F}$ index but, in fact, a continuous variation exists which might be subdivided in many ways. As we have clearly demonstrated, racial differences can be demonstrated using five classes. Using five categories, we further demonstrated that the definition of the size of the $\mathrm{Y}$ as small or large will depend upon race. For example, if an East

TABLE 1 Classification of $Y / F$ indices from normal Caucasians, American blacks, and East Indians.

\begin{tabular}{|c|c|c|c|c|c|c|c|}
\hline \multirow{3}{*}{$\begin{array}{l}\text { Criteria } \\
\text { ( } Y / F \text { indices })\end{array}$} & \multirow[t]{3}{*}{ Size description } & \multicolumn{6}{|c|}{ Size distribution } \\
\hline & & \multicolumn{3}{|c|}{ Sample size } & \multicolumn{3}{|c|}{ Frequency $(\%)$} \\
\hline & & $\begin{array}{l}C \\
(n=60)\end{array}$ & $\begin{array}{l}B \\
(n=60)\end{array}$ & $\begin{array}{l}I \\
(n=70)\end{array}$ & $C$ & $B$ & $I$ \\
\hline $\begin{aligned} \leq & 0.80 \\
& 0.81-0.94 \\
& 0.95-1.09 \\
& 1.10-1.23 \\
> & 1.23\end{aligned}$ & $\begin{array}{l}\text { Very small } \\
\text { Small } \\
\text { Average } \\
\text { Large } \\
\text { Very large }\end{array}$ & $\begin{array}{r}0 \\
9 \\
40 \\
8 \\
3\end{array}$ & $\begin{array}{r}0 \\
2 \\
34 \\
18 \\
6\end{array}$ & $\begin{array}{r}0 \\
1 \\
11 \\
41 \\
17\end{array}$ & $\begin{array}{c}0 \\
15 \cdot 0 \\
66 \cdot 7 \\
13 \cdot 3 \\
5 \cdot 0\end{array}$ & $\begin{array}{l}0 \\
3 \cdot 33 \\
56 \cdot 67 \\
30 \cdot 00 \\
10 \cdot 00\end{array}$ & $\begin{array}{l}0 \\
1 \cdot 42 \\
15 \cdot 71 \\
58 \cdot 57 \\
24 \cdot 28\end{array}$ \\
\hline
\end{tabular}

$\mathrm{C}=$ Caucasian, $\mathrm{B}=$ American black, $\mathrm{I}=$ East Indian. 


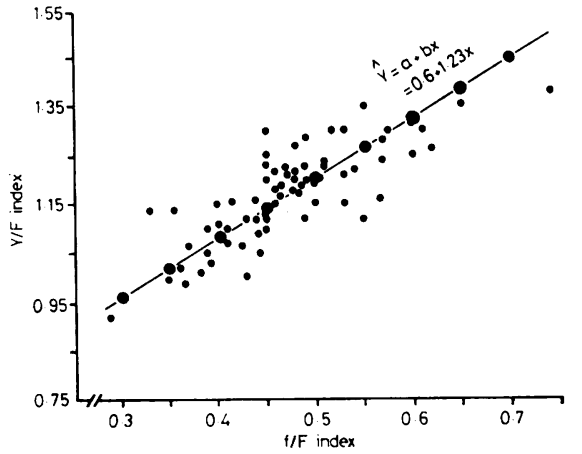

FIG 2 The length of the fluorescent segment of the $Y$ chromosome $(f / F)$ plotted against the length of the $Y$ chromosome $(Y / F)$. Regression line is also drawn.

Indian has a $Y$ which falls in the class of 1.10 to $1 \cdot 23$, his $Y$ will be called average, while that of a Caucasian or black will be called large.

In an attempt to determine the reason for the longer $\mathrm{Y}$ in East Indians, the size of the $\mathrm{f}$ and $\mathrm{nf}$ segments were considered. To examine the heteromorphisms of $\mathrm{f}$ and $\mathrm{nf}$ segments of the $\mathrm{Y}$ chromosome, $\mathrm{f} / \mathrm{F}$ and $\mathrm{nf} / \mathrm{F}$ ratios were also calculated. If the $\mathrm{nf}$ segment of the $\mathrm{Y}$ chromosome is constant in size, then the $\mathrm{nf} / \mathrm{F}$ ratio should not change, since the length of the $F$ group chromosomes is constant. ${ }^{926} \mathrm{~A}$ functional relation between the two variables $(f / F$ vs $Y / F)$ was calculated by using regression coefficient analysis and a regression line was established (fig 2). A test of significance of the regression coefficient was also performed, and it was concluded that highly significant positive regression was present $(p<0 \cdot 01)$. The correlation coefficient (r) was also calculated and tested by the $t$ test. The $r$ was $0.93(p<0.01)$ and the $95 \%$ confidence limit was computed to be 0.8937 to 0.9571 for $f / F$ vs $Y / F$. Consequently, it was concluded that there was a significant correlation between the fluorescent segment and the total length of the $Y$ chromosome. Similar statistics were computed for $\mathrm{nf}$ vs $\mathrm{Y} / \mathrm{F}$ and a similar conclusion was reached. The correlation coefficient was $0.64(p<0.01)$ with a confidence limit of 0.4754 to 0.7595 . The graphic plot is shown in fig 3. The correlation coefficient was also calculated for $\mathrm{f} / \mathrm{F}$ vs $\mathrm{nf} / \mathrm{F}$ indices $(\mathrm{r}=0.05)$ and no significant relation was observed $(p>0.05)$, that is, the $f$ and $\mathrm{nf}$ segments varied independently and there was no relation between them. A graphic plot is shown in fig 4. The mean $Y / F, f / F$, and $n f / F$ indices are $1 \cdot 20,0.47$, and 0.73 , respectively (table 2 ).

Our findings indicate that the length of the $Y$ chromosome is dependent on the $\mathrm{nf}$ as well as the $\mathrm{f}$ segments. Thus, both segments account for an

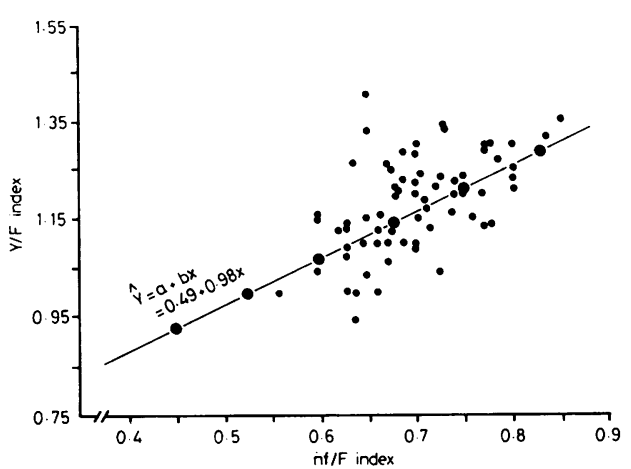

FIG 3 The length of the non-fluorescent segment of the $Y$ chromosome $(n f / F)$ plotted against the length of the $Y$ chromosome $(Y / F)$. Regression line is also drawn.

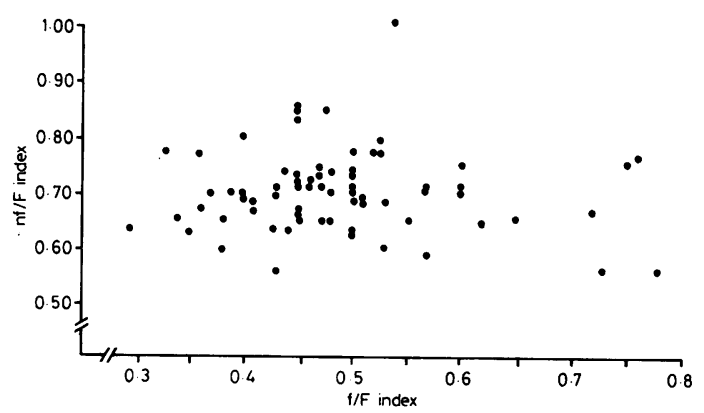

FIG 4 The length of the non-fluorescent segment of the $Y$ chromosome $(n f / F)$ plotted against the length of the fluorescent segment $(f / F)$. No relationship was observed between these two parameters (see text).

increase in the size of the $Y$. However, the longer $Y$ in East Indians was primarily due to the nonfluorescent segment. There was a significant difference in the length of the $\mathrm{nf}$ segment in Indians when compared with Caucasians $(p<0.05)$. Comparison with blacks will not be appropriate since their values are not normally distributed. Furthermore, using the $2 \times N$ contigency $\chi^{2}$ test, the distribution of $Y$ lengths are significantly different $(p<0.05)$. These findings are contrary to the earlier contention that the fluorescent segment accounts for the size variation of the $\mathrm{Y}$ chromosome while the non-fluorescent region is stable. ${ }^{10}$ No relation between the size of the $\mathrm{f}$ and $\mathrm{nf}$ segments was observed; in other words they varied independently.

In man only two genes have been assigned to the $Y$ chromosome. ${ }^{27} 28$ The TDF (testis determining factor) is located on the short arm while the $\mathrm{H}-\mathrm{Y}$ (histocompatibility antigen) gene is located in the non-fluorescent (nf) segment of the long arm of the 
TABLE 2 Comparison of statistical parameters between Caucasians, American blacks, and East Indians.

\begin{tabular}{|c|c|c|c|}
\hline Components & Caucasians & American blacks & East Indians \\
\hline \multicolumn{4}{|l|}{ Index } \\
\hline $\mathbf{Y} / \mathbf{F}$ & $1.02 \pm 0.09$ & $1 \cdot 09 \pm 0 \cdot 10$ & $1 \cdot 20 \pm 0 \cdot 10$ \\
\hline$f / F$ & $0.44 \pm 0.07$ & $0.42 \pm 0.09$ & $0.47 \pm 0.08$ \\
\hline $\mathrm{nf} / \mathrm{F}$ & $0.57 \pm 0.04$ & $0.67 \pm 0.04$ & $0.73 \pm 0.06$ \\
\hline \multicolumn{4}{|l|}{ Correlation (r) } \\
\hline $\mathrm{f} / \mathrm{F}$ vs $\mathrm{Y} / \mathrm{F}$ & 0.86 & 0.89 & 0.93 \\
\hline nf $/ F$ vs $Y / F$ & 0.63 & 0.53 & 0.64 \\
\hline $\mathrm{f} / \mathrm{F}$ vs nf/F & 0.26 & 0.22 & 0.05 \\
\hline \multicolumn{4}{|l|}{ Confidence limit } \\
\hline $\mathrm{f} / \mathrm{F}$ vs $\mathrm{Y} / \mathrm{F}$ & $0.9154-0.7818$ & $0.9329-0.8210$ & $0.9571-0.8937$ \\
\hline nf $/ F$ vs $Y / F$ & $0.7616-0.3876$ & $0.6874-0.3131$ & $0.7595-0.4754$ \\
\hline $\mathrm{f} / \mathrm{F}$ vs nf $/ \mathrm{F}$ & $0.4831-0.0750$ & $0.4470-0.0385$ & $0.2840-0.1868$ \\
\hline
\end{tabular}

chromosome. This raises the question of whether the size of the nf segment has any phenotypic effect, especially when it is either too long or too short. The present study suggests that $\mathrm{nf}$ and $\mathrm{f}$ segments do not have any clinical effect. The reason for the heteromorphic size of the long arm of the $\mathrm{Y}$ chromosome is generally thought to be the result of deletion. ${ }^{29-32}$ Muldal and Ockey ${ }^{30}$ came to this conclusion because of the lack of the distal portion of the $Y$ chromosome. Wahlstrom ${ }^{33}$ observed that extremely short $\mathrm{Y}$ chromosomes did not fluoresce brightly at their distal end by the QFQ technique. There is sufficient evidence to conclude that the bright segment (f) contains large amounts of repetitive DNA $^{34-36}$ and can be further subdivided into several bands ${ }^{37}{ }^{38}$; the size variation in these sub-bands could be a repeat in the tandem arrangement. The mechanism generating length variation of the $\mathrm{nf}$ segment is not clear at present.

The biological significance of variation in the length of the $\mathrm{Y}$ chromosome is not clear. ${ }^{39}$ The observed group differences might indeed represent true chromosomal heteromorphisms, but the factor that maintains this heteromorphism in the population is not known. ${ }^{40}$ Lubs and Patil ${ }^{41}$ suggested that there exists a north/south gradient in the length of the $Y$ in Europeans, men of Mediterranean origin having a longer Y. Furthermore, some investigators have found a longer $\mathrm{Y}$ in criminals, ${ }^{42}$ while others have not found any length differences between criminal and non-criminal controls. ${ }^{43}{ }^{44}$ It has also been suggested that long $Y$ chromosomes may be an important cause of fetal loss. ${ }^{15} 46$ Recently, a higher incidence of a small $Y$ chromosome in humans with trisomy 21 has been reported and it is speculated that fathers with a small $Y$ chromosome might be at higher risk for nondisjunction for chromosome $21 .^{47}$

The present study clearly demonstrates that racial variation in the length of the $\mathrm{Y}$ chromosome is the result of variation in both the non-fluorescent and fluorescent segments, and future studies should attempt to determine if variation in the $\mathrm{nf}$ segment plays a role in fetal loss or other clinical parameters. In summary, this study provides measurement data on $\mathrm{nf}$ and $\mathrm{f}$ segments in a normal East Indian population and compares these data with other normal as well as abnormal populations.

We are highly indebted to Professor E R Sears of the University of Missouri-Columbia, Missouri, USA for his valuable suggestions. The technical assistance of Mr Jorge Rodriguez is gratefully appreciated.

\section{References}

1 Denver Conference. A proposed standard system of nomenclature of human mitotic chromosomes. Lancet $1960 ; \mathbf{i}: 1063-5$.

2 Makino S, Muramoto, T. Some observations on the variability of the human Y chromosome. Proc Jpn Acad 1964;40:757-61.

${ }^{3}$ Cohen MM, Shaw MW, MacClure JW. Racial differences in the length of the human Y chromosome. Cytogenetics $1966 ; 5: 34-52$

4 Bishop A, Blank CE, Hunter H. Heritable variation in the length of the Y chromosome. Lancet 1962;ii:18-22.

5 de la Chapelle A, Hortling H, Edgren J, Kaariainen R. Evidence for existence of heritable large $Y$ chromosomes unassociated with developmental disorder. A cytogenetical and clinical study of four males with hypogonadism, one with mongolism and their relatives. Hereditas 1963;50:351-60.

6 McKenzie WH, Hostetter TL, Lubs HA. Y family study: heritable variation in the length of the human $Y$ chromosome. Am J Hum Genet 1972;24:686-93.

- Caspersson T, Lomaka L, Zech L. The 24 fluorescence patterns of the human metaphase chromosomes distinguishing characters and variability. Hereditas 1971 ; 67:89-102.

8 Paris Conference (1971). Standardization in human cytogenetics. Birth Defects 1972;Vlll:No 7.

9 ISCN. An international system for human cytogenetic nomenclature. Birth Defects 1978;XIV:No 8.

10 Bobrow M, Pearson PL, Pike MC, El-Alfi OS. Length variation in the quinacrine banding segment of different size. Cytogenetics $1971 ; 10: 190-8$.

11 Laberge C, Gagne R. Quinacrine mustard staining solves the length variations of the human $Y$ chromosome. Johns Hopkins Med J 1971 ;128:79-83. 
12 Robinson JA, Buckton KE. Quinacrine fluorescence of variant and abnormal human $Y$ chromosome. Chromosoma 1971;35:340-2.

13 Knuntila S, Gripenberg V. The fluorescence pattern of human Yq+ chromosome. Hereditas 1972;70:307-8.

14 Nielsen J, Friedrich V. Length of the $Y$ chromosome in criminal males. Clin Genet $1972 ; 3: 281-5$.

15 Schnedl W. Fluoreszenzunterschugen uber die langeuariabiliatat des Y chromosomes beim menschen. Hum Genet $1971 ; 12: 188-94$.

16 Soudek D, Langmuir V, Stewart DJ. Variation in the non-fluorescent segment of long $\mathrm{Y}$ chromosome. Hum Genet $1973 ; 18: 285-90$.

17 Verma RS, Dosik H, Scharf T, Lubs HA. Length heteromorphisms of fluorescent (f) and non-fluorescent (nf) segments of human $Y$ chromosome: classification, frequencies, and incidences in Caucasians. $J$ Med Genet $1978 ; 15: 277-81$.

18 Verma RS, Evans-McCalla M, Dosik H. Human chromosomal heteromorphisms in American blacks. VI. Higher incidence of longer $Y$ owing to non-fluorescent (nf) segment. J Med Genet 1982;19:297-301.

19 Verma RS, Rubenstein CT, Dosik H. Effect of $\mathrm{CO}_{2}$ on short term human lymphocyte culture in vitro. In Vitro 1977;13:806-7.

20 Verma RS, Lubs HA. A simple R banding technique. Am J Hum Genet 1975;27:110-7.

21 Verma RS, Lubs HA. Additional observations on the preparation of R-banded human chromosomes with acridine orange. Can J Genet Cytol 1976;18:45-50.

22 Verma RS, Dosik H. An improved method of photographing human fluorescent chromosomes. $J$ Microsc 1976;108:339-41.

23 Verma RS, Dosik $H$. The technical variables associated with the frequencies of QFQ, RFA, and CGB heteromorphisms of human chromosomes. Clin Genet 1979;15: 450-3.

24 Sokal RR, Rohlf FJ. Biometry. The principles and practice of statistics in biological research. San Francisco: Freeman, 1969.

25 Court-Brown WM. Human population cytogenetics. Amsterdam: North-Holland, 1967.

26 Ledley RS, Lubs HA, Ruddle FH. Introduction to chromosome analysis. Comput Biol Med 1972;2:107-28.

27 McKusick VA. The anatomy of human genome. $J$ Hered 1980;71:370-91.

${ }^{28}$ McKusick VA. Ruddle FH. The status of the gene map of the human chromosomes. Science 1977;196:390-405.

29 Conen PE, Bailey JD, Allemang WH, Thompson DW, Ezrin C. A probable partial deletion of the Y chromosome in an intersex patient. Lancet 1961 ;ii:294-5.

30 Muldal S, Ockey $\mathbf{C H}$. Deletion of $\mathrm{Y}$ chromosome in a family with muscular dystrophy. Br Med J 1962;1:291-4.
31 Nakagome $Y$, Sasaik $M$, Matsui I, Kawazura $M$, Fukuyam Y. A mentally retarded boy with a minute $Y$ chromosome. J Pediatr 1965;67:1163-7.

32 Genest P, Laberge C, Poty J, Gagne R, Bouchard M. Transmission d'un petit " $Y$ " durant onze generations dans une lignee familiale. Ann Genet (Paris) 1970;13: 233-8.

33 Wahlstrom J. Are variations in the length of $Y$ chromosome due to structural changes? Hereditas 1971; 69:125-8.

34 Pardue ML, Gall JG. Chromosomal localization of mouse satellite DNA. Science 1970;168:1356-8.

35 Arrighi FE, Hsu TC. Localization of heterochromatin in human chromosome. Cytogenetics 1971 ;10:81-6.

36 Yunis JJ, Rolda L, Yasmineh WG, Lee JC. Staining of satellite DNA in metaphase chromosome. Nature 1971; 231:532-3.

37 Jalal SM, Pfeiffer RA, Pathak S, Hsu TC. Subdivision of the human $Y$ chromosome. Humangenetik 1974;24: 59-65.

38 Yunis JJ. High resolution human chromosomes. New York: Academic Press, 1982.

39 Verma RS, Dosik H. Human chromosomal heteromorphisms: nature and clinical significance. Int Rev Cytol 1979;62:361-83.

40 Monsolve MV, Erdtmann B, Ott PA. Frota-Pessoa O. The human Y chromosome: racial variation and evolution Rev Bras Genet 1980;4:433-46.

41 Lubs HA, Patil SR. Mediterranean origin of long $Y$ chromosomes in Caucasians. Am J Hum Genet 1975;27: $60 \mathrm{~A}$.

42 Soudek D, Laraya P. Longer Y chromosome in criminals. Clin Genet 1974;6:225-9.

43 Benezech M, Noel B, Travers E, Mottet J. Conduite antisociale et longueur du chromosome Y. Hum Genet $1976 ; 32: 77-80$.

44 Brogger A, Urdal T, Larsen FB, Lavik NJ. No evidence for a correlation between behavior and the size of the $Y$ chromosome. Clin Genet 1977;11:349-58.

45 Patil SR, Lubs HA. A possible association of long $Y$ chromosome and fetal loss. Hum Genet 1977;35:233-5.

46 Nielsen J. Large $\mathrm{Y}$ chromosome $(\mathrm{Yq}+)$ and increased risk of abortion. Clin Genet 1978;13:415-6.

47 Verma RS, Huq A, Madahar C, Qazi Q, Dosik H. Higher incidence of small $\mathrm{Y}$ chromosome in humans with trisomy 21 (Down syndrome). Pediatr Res 1982;16: 769-70.

Requests for reprints to Dr Ram S Verma, Division of Cytogenetics, The Jewish Hospital and Medical Center, 555 Prospect Place, Brooklyn, NY 11238, USA. 